\title{
The referee who agrees to review and never responds again (NERO): a series of 37 cases of an emerging entity
}

\author{
Werner Paulus ${ }^{1}$
}

Published online: 6 March 2018

c) Springer-Verlag GmbH Germany, part of Springer Nature 2018

One of the most interesting and satisfying aspects of my work as editor of Acta Neuropathologica is the interaction with referees. I have the greatest admiration for our referees who, in spite of many other obligations, spend some of their precious free time to undertake careful, critical, constructive and insightful reviews anonymously and without compensation. When reading through referees' comments, I learn a lot not only about science, but remarkably often also about the personality of the referee. I have the feeling that I know many of the referees without having met them in person.

Besides the vast majority of referees who are doing a great job, there are a few referees who exhibit curious behavioral traits. These referees include, for example, the offended author whose paper had been rejected recently and who then states a lack of willingness to undertake any reviews for this journal. Or the "cite three of my papers and everything is fine" referee. Here, I will focus on another type of referee who appears to have increased in number during the past few years and may affect the prosperity of a journal.

These referees agree to review a paper via the Editorial Manager system. After the usual due date of 14 days, they receive several automatic reminders, followed by reminders that I individualize, and then personal e-mails. In some cases, I try to reach the referees by phone or leave a message, but they are inaccessible. These referees never respond. They are then un-invited via an e-mail message, usually between 30 and 45 days following their agreement to review (and about 15-35 days after the due date). Even after being uninvited, there is still no feedback. The referees appear to have virtually dissolved or disappeared.

I designate these referees as NEROs (for "NEver RespOnding"). This acronym also refers to the Roman Emperor Nero who is known for his exclamation "Oh, that I

Werner Paulus

werner.paulus@uni-muenster.de

1 Institute of Neuropathology, University Hospital Münster, Pottkamp 2, 48149 Münster, Germany could not write" (thereby signifying his aversion to signing death sentences; an attitude that later changed). It remains open to speculation whether our NERO's unwillingness to write the review may be similarly related to an aversion to being responsible for a paper's negative outcome in the review process (although I guess there are more probable explanations).

To gain more insight into the pathomechanisms and because no experimental model of NERO exists, I have undertaken a retrospective analysis using the Editorial Manager system for Acta Neuropathologica. Ethical approval was not obtained. Among a total of 6565 referees included in the database, 37 NEROs were identified (0.6\%). Interestingly, only a single neuropathologist was revealed as a NERO, while the other 36 NEROs comprised clinical neuroscientists such as neurologists or (more commonly) $\mathrm{PhD}$ neuroscientists. My interpretation is not that neuropathologists are more reliable persons than other neuroscientists (although I would sympathize with this conclusion if correct). It is more probable that "inappropriate" behavior is more common when it is anonymous rather than within a relatively closed circle where personal interaction is expected to occur in the future. I had invited 35 of 37 NEROs for the first time as potential referees for Acta Neuropathologica, while the other two had submitted a review before. Otherwise, there was no apparent difference between NEROs and other referees with respect to geography, stage of career (ranging from the young post docs to the retired professors), or gender.

I then tried to obtain follow-up information from NEROs, usually several months or years after the un-invitation, explaining the background of my analysis and asking about reasons for not responding and about suggestions for preventing non-responsive behavior of referees. Ten of 37 (27\%) referees responded. Most of them stated they did not remember and apologized for having been non-responsive. Submitted reasons for not responding included overload with work at this time $(n=6)$, potential problems with the e-mail account (2), family issues (1) and the fact that the amount 
of work that goes into reviewing articles receives neither reward nor recognition (2). Suggestions forwarded by referees include more frequent reminders before the deadline, the option to import the due date into the referee's electronic calendar, and mailing a pdf of the manuscript without the need to $\log$ in.

Among the other 27 referees who did not respond to my follow-up mail were two who apparently left science and one who passed away. I checked website and e-mail addresses for the remaining 24 NEROs and found that they are apparently still in business and active. I can only speculate why they never responded. One option is that they had been interested in the identity of authors of the paper (author names are not revealed in review invitations) and/or in obtaining access to full data, possibly because they had been undertaking a similar study at that time. Maybe they had a serious personal problem or vital and unforeseen obligations. Or they may be just poorly organized. I do not know.

It can be argued that NEROs not only delay the review process and prove a disservice to the community, but they may even constitute scientific misbehavior. Should it be scrutinized and prosecuted, like plagiarism or manipulation of figures? I do not think so. Approaching the institutions of NEROs or exchanging names among journals is certainly not an option, because our review process is confidential and anonymous, and some NEROs may indeed have acceptable and understandable reasons for not responding, such as illness or other personal issues.

Are there preventative strategies for recognizing potential NEROs? Not really, I am afraid. I perform a PubMed and Internet search for each new submission to identify the most appropriate referees, and over the years I have developed a gut feeling of whether a potential referee will accept the review invitation and deliver a good review. Nonetheless I am not able to prevent occasional poor reviews and uncooperative referees. What I have done is to mark NEROs in the database, so that they are not invited for another review. During the process of analyzing NEROs for this editorial, I have intentionally invited one of the NEROs for reviewing a new paper. Interestingly, the referee agreed to review and again behaved as NERO, suggesting that the condition in at least a core group may be chronic or even progressive.

What is most remarkable to me, however, is not the finding that $0.6 \%$ of referees are NEROs. I am more impressed that more than $99 \%$ of referees are reliable and contribute to improving science based on compassion and dedication for neuroscience and neuropathology. And if anything is good about NEROs, it is that their rarity helps me to realize that, contrary to widespread belief, peer review works very well, at least in this journal. 